\title{
Molecular and MALDI-TOF MS identification of swallow bugs Cimex hirundinis (Heteroptera: Cimicidae) and endosymbionts in France
}

Fatima Zohra Hamlili, ${ }^{1,2}$, Jean-Michel Bérenger ${ }^{1,2}$, Adama Zan Diarra ${ }^{1,2}$ and Philippe Parola ${ }^{1,2^{*}}$ (D)

\begin{abstract}
Background: The Cimicidae are obligatory blood-feeding ectoparasites of medical and veterinary importance. We aim in the current study to assess the ability of MALDI-TOF MS to identify Cimex hirundinis swallow bugs collected in house martin nests.

Methods: Swallow bugs were picked out from abandoned nests of house martin swallows and identified morphologically to the species level. The bugs were randomly selected, dissected and then subjected to MALDI-TOF MS and molecular analyses.
\end{abstract}

Results: A total of 65 adults and 50 nymphs were used in the attempt to determine whether this tool could identify the bug species and discriminate their developmental stages. Five adults and four nymphs of $C$. hirundinis specimens were molecularly identified to update our MS homemade arthropod database. BLAST analysis of CO/ gene sequences from these C. hirundinis revealed $98.66-99.12 \%$ identity with the corresponding sequences of C. hirundinis of the GenBank. The blind test against the database supplemented with MS reference spectra showed 100\% (57/57) C. hirundinis adults and 100\% (46/46) C. hirundinis nymphs were reliably identified and in agreement with morphological identification with logarithmic score values between 1.922 and 2.665. Ninety-nine percent of C. hirundinis specimens tested were positive for Wolbachia spp. The sequencing results revealed that they were identical to Wolbachia massiliensis, belonging to the new T-supergroup strain and previously isolated from C. hemipterus.

Conclusions: We report for the first time to our knowledge a case of human infestation by swallow bugs (C. hirundinis) in France. We also show the usefulness of MALDI-TOF MS in the rapid identification of C. hirundinis specimens and nymphs with minimal sample requirements. We phylogenetically characterized the novel Wolbachia strain (W. massiliensis) infecting C. hirundinis and compared it to other recognized Wolbachia clades.

Keywords: Cimex hirundinis, MALDI-TOF MS, Swallow bug, Wolbachia, Wolbachia massiliensis, France

${ }^{*}$ Correspondence: philippe.parola@univ-amu.fr

1 IHU-Méditerranée Infection, Marseille, France

Full list of author information is available at the end of the article

(c) The Author(s) 2021. Open Access This article is licensed under a Creative Commons Attribution 4.0 International License, which permits use, sharing, adaptation, distribution and reproduction in any medium or format, as long as you give appropriate credit to the original author(s) and the source, provide a link to the Creative Commons licence, and indicate if changes were made. The images or other third party material in this article are included in the article's Creative Commons licence, unless indicated otherwise in a credit line to the material. If material is not included in the article's Creative Commons licence and your intended use is not permitted by statutory regulation or exceeds the permitted use, you will need to obtain permission directly from the copyright holder. To view a copy of this licence, visit http://creativecommons.org/licenses/by/4.0/. The Creative Commons Public Domain Dedication waiver (http://creativeco mmons.org/publicdomain/zero/1.0/) applies to the data made available in this article, unless otherwise stated in a credit line to the data. 


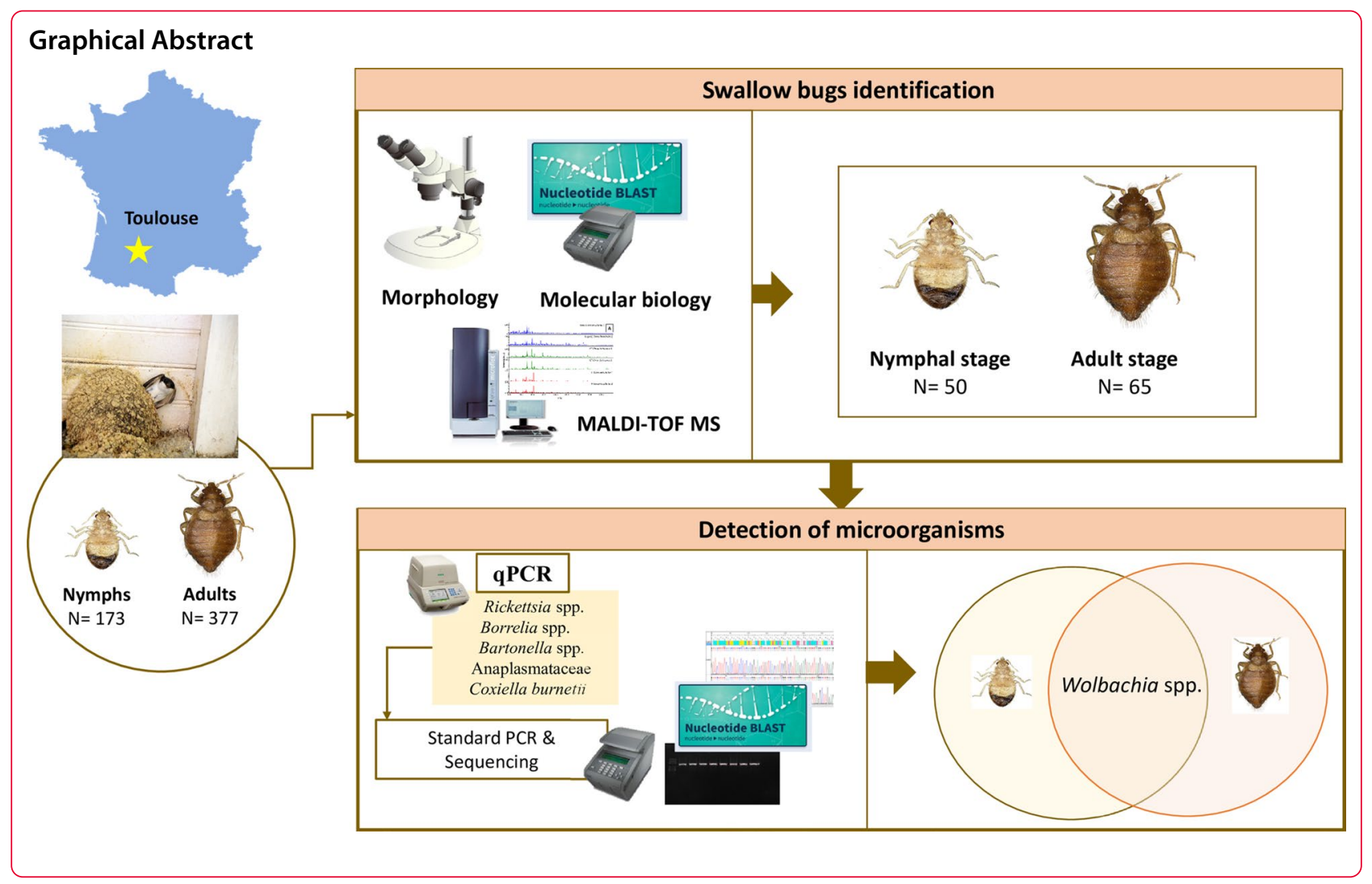

\section{Background}

The "true bugs" refer to the order Hemiptera, with > 42,000 species in 90 families worldwide $[1,2]$. This order comprises insects, including predatory entomophagous insects that feed on insects and small invertebrates, phytophagous insects and three families that are strictly hematophagous [3]. The Cimicidae family includes around 100 species grouped into 24 genera [4]. This family can be differentiated from other Hemiptera by being flat in shape, ovoid, flightless and wingless $[3,5]$.

In Europe, the Cimicinae subfamily is the only one prevalent. It is represented by the genus Cimex, which includes seven species [6,7]. Within the Cimex group, two cosmopolitan species, C. lectularius, the common bed bug, and $C$. hemipterus, the tropical bed bug, feed on human blood [8-10]. Otherwise, Cimex columbarius, $C$. pipistrelli and C. dissimilis occasionally feed on human blood when their preferred hosts (bats and birds) are absent $[6,11,12]$. Three common species are involved in swallow bug infestation: the North American swallow bug $C$. vicarius, which is an ectoparasite of the cliff swallow, rarely reported in the barn swallow and house sparrow [13-16]; Cimex hirundinis, which is found in Eurasia, exclusively common to house martin nests and other birds; Cimex montandoni, which is found specifically in Romania in sand martin nests [7, 17]. Cimex vicarius is the only known vector of Buggy Creek virus (BCRV; Togaviridae, Alphavirus), which causes western equine encephalitis [18, 19]. Another arbovirus, the strain responsible for Venezuelan equine encephalitis (Tonate virus), has also been isolated in $C$. vicarius [20].

Under certain conditions, $C$. hirundinis are able to feed on human blood, and their bite is known to be more painful than that of bedbugs $[6,7,21,22]$. However, except for experienced entomologists, it is challenging to make a morphological distinction between Cimex spp. and even other arthropods. In addition, the number of entomologists is declining, and adapted documentation is sometimes not accessible [23]. The molecular approach has been assessed for its potential to overcome these limitations. Conversely, the molecular tool is relatively laborious, requires high-cost reagents and depends on both the availability of highquality reference sequences in the GenBank database and the use of the correct gene fragment [23-25].

Over the past decade, the matrix-assisted laser desorption/ionization time-of-flight mass spectrometry (MALDI-TOF MS) technique has widely revolutionized the clinical microbiology field [26]. It has also emerged 
in medical entomology. MALDI-TOF MS has been shown to be rapid, reliable and notably inexpensive (as soon as the device is available) for identifying various species of arthropods [27]. Recently, Benkacimi et al. [25] showed that this innovative tool could be used as an alternative method to identify and discriminate between C. hemipterus and C. lectularius.

Our study aimed to assess the ability of MALDI-TOF MS to identify swallow bugs collected from abandoned house martin nests in France. Molecular tools were also used to identify these swallow bugs and screen them for carriage of microorganisms.

\section{Methods}

\section{Swallow bugs sampling and morphological identification}

Five hundred swallow bugs were sampled from abandoned swallow nests in a house located in Toulouse $\left(43^{\circ} 36^{\prime} 16^{\prime \prime} \mathrm{N}, 1^{\circ} 26^{\prime} 38^{\prime \prime} \mathrm{E}\right)$ in southwest France in July 2020 (Fig. 1a). The house martin swallows [Delichon urbicum (Passeriformes, Hirundinidae)] built jugshaped mud nests under the eaves of the house, represented in Fig. 1b. The sampling was conducted in highly infested nests (Fig. 1c-e). Abandoned nests were placed in plastic storage containers, carefully transported to the insectarium of Marseille and broken into small pieces to pick out the swallow bugs. The swallow bugs were harvested using forceps, counted and then stored at $-20{ }^{\circ} \mathrm{C}$. The morphological identification to the species level was assessed and confirmed by an expert entomologist (JMB) using the identification keys [6,
7]. A VHX-7000 digital microscope (Kayence, Osaka, Japan) and electron microscope (SEM Hitachi TM4000 Plus) were used to photograph morphological details. For the analysis, the insect stage and species were codified on the tube.

\section{DNA extraction and molecular identification of swallow bugs}

DNA extraction was performed from the half body of each specimen using an EZ1 DNA Tissue Kit (Qiagen) following the same DNA extraction protocol as described by Benkacimi et al. [25]. The swallow bug specimens (nymphs and adults) added into the MS reference database were subjected to standard PCR in an automated DNA thermal cycler (Applied Biosystems, 2720, Foster City, CA, USA) using Folmer's universal COI (cytochrome oxidase subunit I) barcoding primers (LCO1490, HCO2198) targeting 710 base pairs [28]. The thermocycler program used for the amplification of the COI was previously described by Benkacimi et al. [25]. The sequences obtained were used to perform BLAST searches [29] via the National Center for Biotechnology Information (NCBI) GenBank sequence and were then aligned using MEGA7 [30]. A phylogenetic tree was constructed and edited using the maximum likelihood method with model selection determined by MEGA7 and Figtree 1.4.2, respectively [30-32]. Statistical support for internal branches of the trees was evaluated by bootstrapping with 500 iterations.

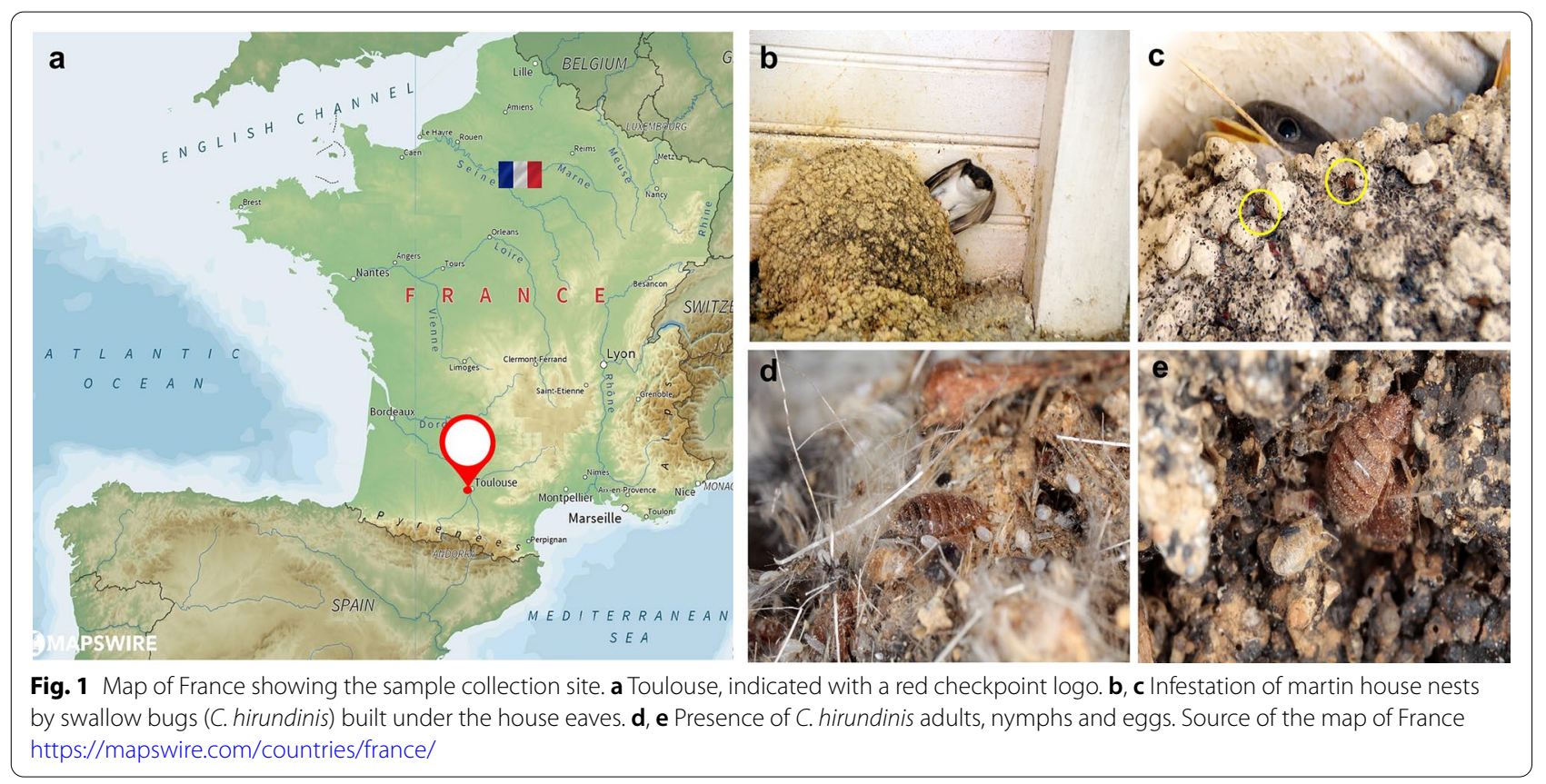




\section{MALDITOF MS sample preparation for analysis}

Specimens of swallow bugs $(n=115)$ were rinsed successively in $70 \%$ ethanol followed by two baths of distilled water and were dried on sterile filter paper [25]. The heads of adults $(n=65)$ and the cephalothoraces (head and thorax) of nymphs $(n=50)$ were dissected under a Leica ES2 stereomicroscope $10 \times / 30 \times$ using a new sterile blade. They were then immersed for $2.5 \mathrm{~min}$ in distilled water, rinsed with distilled water and immersed for $2 \mathrm{~min}$ in $200 \mu \mathrm{l}$ of $70 \%$ formic acid and $200 \mu \mathrm{l}$ of $50 \%$ acetonitrile. The dissected parts were dried on sterile filter paper for MALDI-TOF MS analysis [25]. The remaining body parts were conserved at $-20{ }^{\circ} \mathrm{C}$ for molecular biology and supplementary analysis. The cephalothoraces were homogenized in $15 \mu \mathrm{l}$ and the heads in $40 \mu \mathrm{l}$ of the extraction solution (70\% formic acid and 50\% acetonitrile) using glass beads (1.0 mm diameter, BioSpec Products). All preparations were homogenized using the TissueLyser instrument (Qiagen, Germany). One microliter of the supernatant of the protein extract from each sample was spotted in quadruplicate on a MALDI-TOF MS steel target plate (Bruker Daltonics, Germany). The spots were left to dry and then covered with $1 \mu \mathrm{l}$ of matrix solution composed of saturated $\alpha$-cyano-4-hydroxycynnamic acid (Sigma, Lyon. France), 50\% acetonitrile, 2.5\% trifluoroacetic acid and HPLC-grade water [33]. The target plate was dried at room temperature before being inserted into the MALDI-TOF MS instrument (Bruker Daltonics, Germany) for analysis.

\section{MALDI-TOF MS parameters}

Protein mass profiles were generated using a Microflex MALDI-TOF mass spectrometer (Bruker Daltonics) with Flex Control software (Bruker Daltonics), with parameters previously described [34]. The profiles of the spectra obtained were viewed using Flex Analysis, version 3.3, and MALDI Biotyper, version 3.0, software and ClinProTools v.2.2 for data processing.

\section{MALDI-TOF MS analysis and reference database creation}

The reproducibility of the MS spectra generated from adult and nymph swallow bugs was visualized with Flex analysis v.3.3 and then exported to ClinProTools v.2.2 software packages (Bruker Daltonics, Germany) for data processing (smoothing, baseline subtraction) [25]. Intraspecies reproducibility and inter-species specificity were assessed by comparing and analyzing the spectral profiles obtained from the four spots of each individual specimen. Spectra of bad quality were excluded from the analysis $[<3000$ arbitrary units (a.u.)]. An MS dendrogram was created using MALDI-Biotyper software v.3.0 to visualize the heterogeneity level of MS spectra from adult and nymph swallow bugs (hierarchical clustering of the mass spectra). Good-quality spectra (high peak intensity and reproducibility) were then added to our MALDI-TOF MS in-house database after being molecularly confirmed.

\section{Blind tests}

The blind test was performed (MALDI-Biotyper software v.3.0, Bruker Daltonics) using swallow bug specimens, with the exception of those used as MS reference spectra. The accuracy of species identification was evaluated using obtained log-score values (LSVs). This value can range from 0 to 3 . The spectrum with the highest log score value [LSV] among the four spots was selected as a valid identification [33].

\section{Microorganism detection in swallow bugs}

DNA from 115 swallow bugs, including 65 adults and 50 nymphs, was screened by qPCR using primers and probes targeting specific sequences of the following bacterial pathogens: Rickettsia spp. (RKND03), Borrelia spp. (Bor 16S), Bartonella spp. (Barto ITS2) and Coxiella burnetii (IS30A), Anaplasmataceae spp. (23S rRNA) [33]. Positive samples for Anaplasmataceae spp. were then submitted to the qPCR system specific for detecting Wolbachia spp. [35]. For each qPCR plate, negative (qPCR reaction mix without DNA) and positive (DNA from our laboratory cultures) controls were used. Four Wolbachia-positive samples were submitted to standard PCR targeting 438 base pair fragments of $16 S$ rRNA [36] and targeting 560 base pair fragments of the fts $Z$ gene [37] (Table 1) and sequencing to identify Wolbachia species. Phylogenetic analyses based on $16 S$ rRNA and fts $Z$ gene sequences were performed using the maximum likelihood method and the model selected by MEGA7 [30, 31, 38]. Statistical support for internal branches of the trees was assessed by

Table 1 Primers used for Wolbachia sequencing

\begin{tabular}{|c|c|c|c|c|c|c|}
\hline Microorganism & Target gene & Primer & Sequence $\left(5^{\prime}-3^{\prime}\right)$ & $\operatorname{Tm}\left({ }^{\circ} \mathrm{C}\right)$ & $\begin{array}{l}\text { Amplicon size } \\
\text { (bp) }\end{array}$ & References \\
\hline \multirow[t]{2}{*}{ Wolbachia spp. } & 16S rRNA & $\begin{array}{l}\text { W-Specf } \\
\text { W-Specr }\end{array}$ & $\begin{array}{l}\text { CATACCTATTCGAAGGGATAG } \\
\text { AGCTTCGAGTGAAACCAATTC }\end{array}$ & 60 & 438 & {$[36]$} \\
\hline & $\mathrm{fts} Z$ & $\begin{array}{l}\text { Wol.ftsZ.363.f } \\
\text { Wol.ftsZ.958.r }\end{array}$ & $\begin{array}{l}\text { GGRATGGGTGGTGGYACTGG } \\
\text { GCATCAACCTCAAYARAGTCAT }\end{array}$ & 59.50 & 560 & {$[37]$} \\
\hline
\end{tabular}


bootstrapping with 1000 iterations (only bootstrap values $\geq 50$ were retained).

\section{Results \\ Morphological characterization}

In total, 550 bugs were picked out from abandoned nests: 377 adults and 173 nymphs. Adult specimens were morphologically identified as $C$. hirundinis. They were characterized by the presence of long, pale bristles and less protruding eyes (Fig. 2a and b). Compared to our laboratory-reared bed bugs, they were smaller and more pubescent (Fig. 2a), and the anterior lobes of the pronotum (Fig. 2b) were moderately developed compared to the bed bug pronotums (Fig. $2 \mathrm{c}$ and d). The scanning electron microscope analysis revealed a detailed visualization of the species. The pronotum of C. hirundinis (Fig. 2j) compared to C. lectularius and C. hemipterus is remarkably less concave. At the pronotum sides, the bristles of C. hirundinis (Fig. 2i) are fine, longer and more numerous than the bed bug bristles (Fig. 2e and g), including on the whole-body surface (Fig. 2a and b). The C. lectularius pronotum bristle shape (forked-sharpened, showing jagged crowns) appeared to be identical to $C$. hirundinis pronotum bristles, but they were shorter and thicker
(Fig. 2g and i). However, C. hemipterus bristles seemed to be smoother and not jagged (Fig. 2e). The C. hirundinis male intromittent genital organ is illustrated in Additional file 1: Figure S1a and $\mathrm{c}$ and the female paragenital sinus in Additional file 1: Figure S1b and d. Concerning the nymphs, we grouped the nymphs into stage 2 , stage 3 and stage 4 based on body size (Additional file 2: Figure S2).

\section{Molecular identification of swallow bugs}

The morphological identification of $C$. hirundinis was confirmed by molecular tools. Five sequences of adults and another four sequences of nymphs were successfully obtained using the COI gene. NCBI BLAST analysis of $C O I$ sequences from nine specimens of $C$. hirundinis added to our MALDI-TOF MS in-house database revealed that they were 98.66-99.12\% identical to Oeciacus hirundinis (GenBank accession nos. MG596808-GU985544) (Table 2). To see the position of the obtained sequences among the GenBank COI sequences, a phylogenetic tree was constructed on the basis of $C O I$ fragment sequences. The phylogenetic tree showed that the sequence of $C$. hirundinis clustered with the sequence of $O$. hirundinis deposited in the GenBank

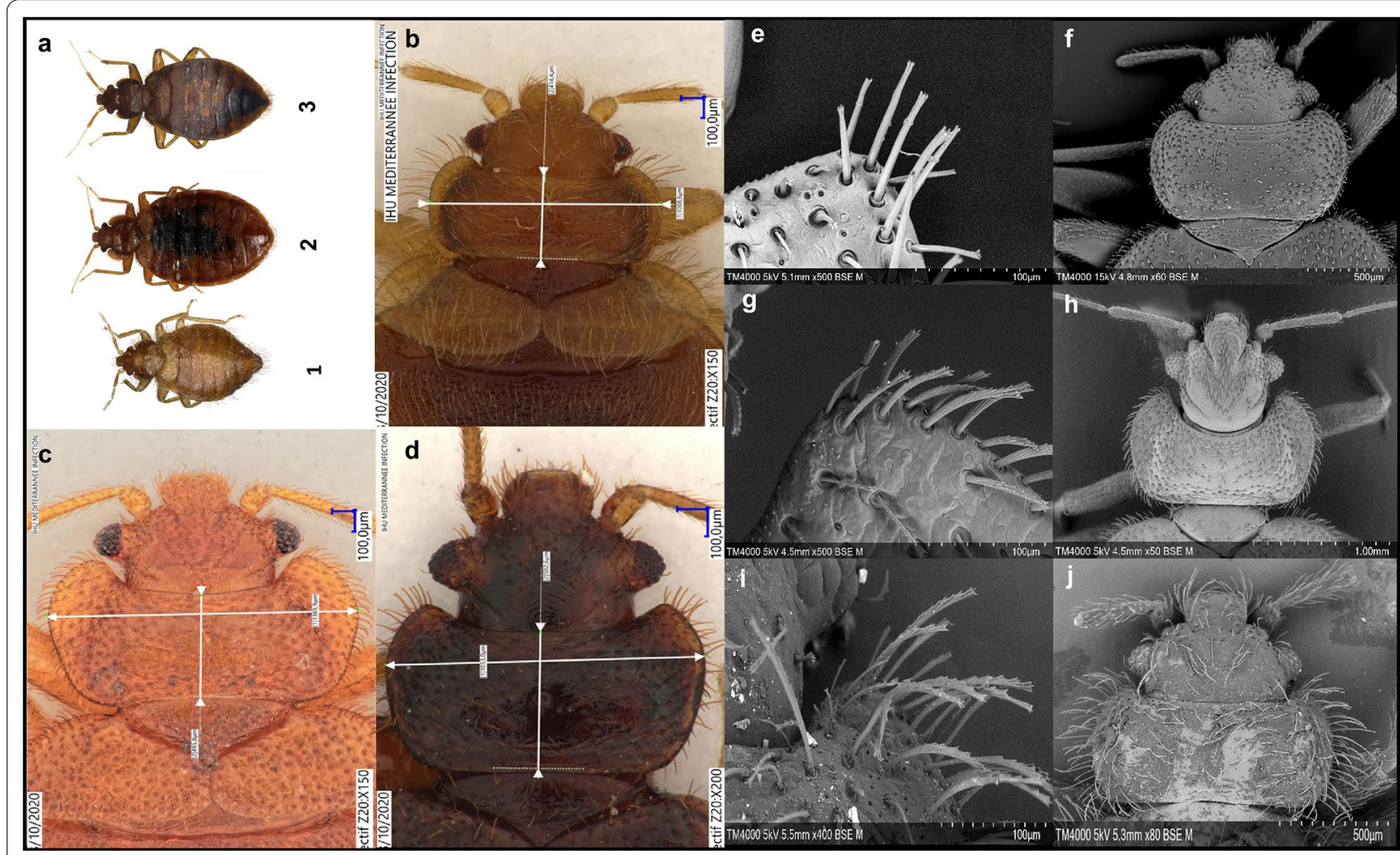

Fig. 2 Digital microscope (DM) and scanning electron microscope images (SEM) of a swallow bug and laboratory-reared bed bugs. a Dorsal view representation of C. hirundinis (1), laboratory-reared C. lectularius (2) and C. hemipterus (3). b Pronotum of C. hirundinis (b), C. lectularius (c) and C. hemipterus (d). Pronotal bristles and pronotum of C. hemipterus (e and $\mathbf{f}$ ), C. lectularius ( $\mathbf{g}$ and $\mathbf{h}$ ) and C. hirundinis (i and $\mathbf{j})$ 


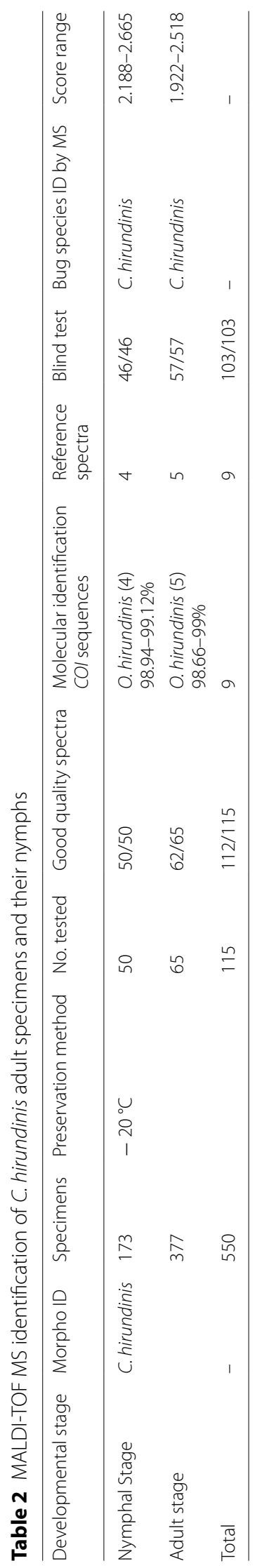


and grouped in the Cimicinae subfamily (Fig. 3). The sequences of the COI gene of $C$. hirundinis were deposited in the GenBank. The FASTA of the COI sequence is attached in Additional file 3: Dataset S1.

\section{Comparison of $C$. hirundinis adults and nymphs}

Sixty-five specimens of adults and 50 nymphs (stage 2, 3 and 4), randomly selected, were subjected to MALDITOF MS to identify the specimens and assess the

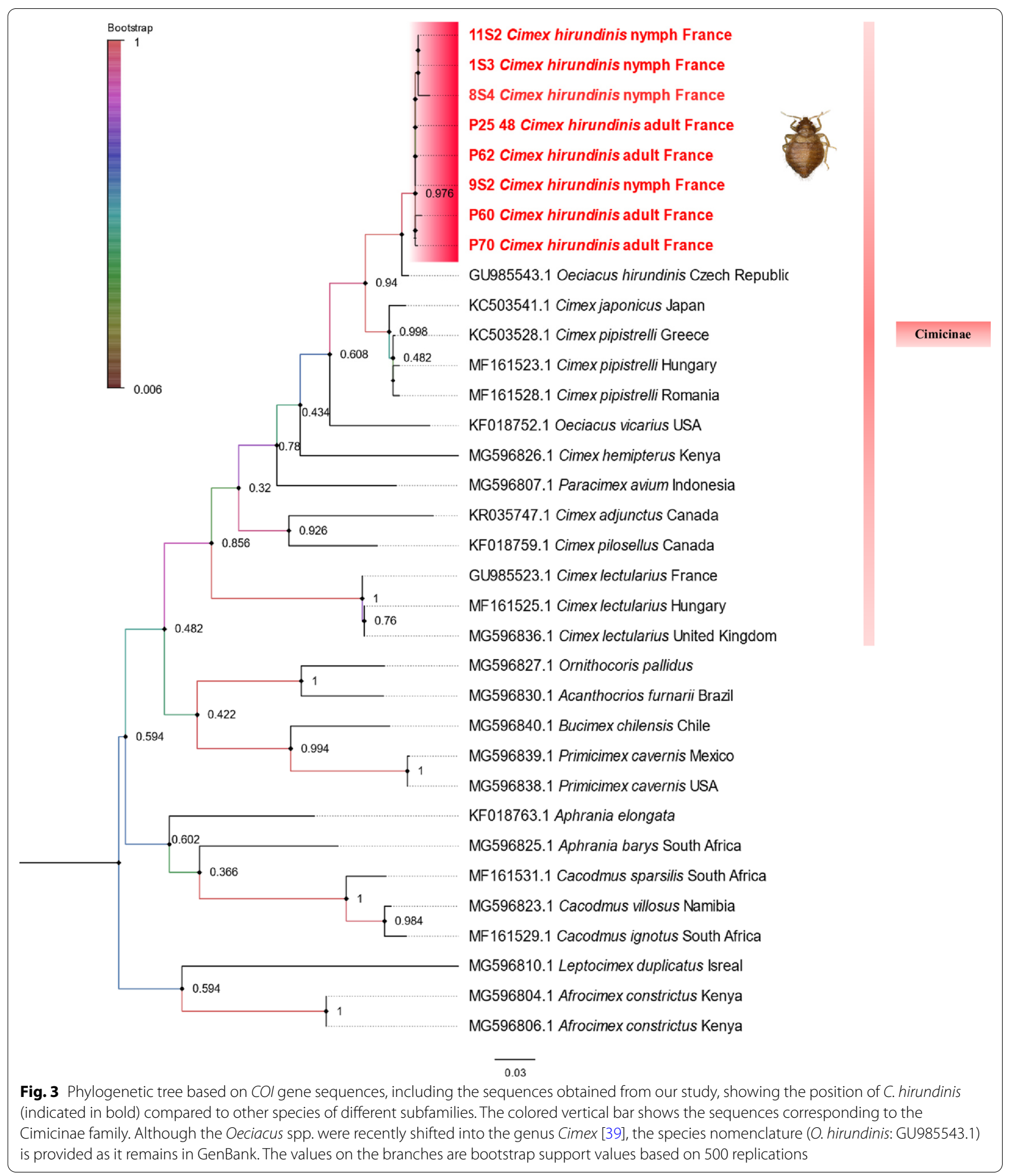


reproducibility as well as the specificity of MS spectra. Spectral profile analysis using Flex analysis software showed that $62 / 65$ (95.38\%) of $C$. hirundinis at the adult stage and 50/50 (100\%) nymphs provided good-quality MS spectra (Table 2) (Fig. 4a). The principal component analysis using ClinProTools v.2.2 software revealed a clear distinction between nymphal and adult stages
(Fig. 4b). The results were confirmed by the MS dendrogram (Fig. 5a) using MALDI-Biotyper 3.0. The MS protein profiles of both stages revealed sufficient discrimination between the MS spectra of adults and nymphs. However, clustering was not obtained for the nymphal stages (Fig. 5a).
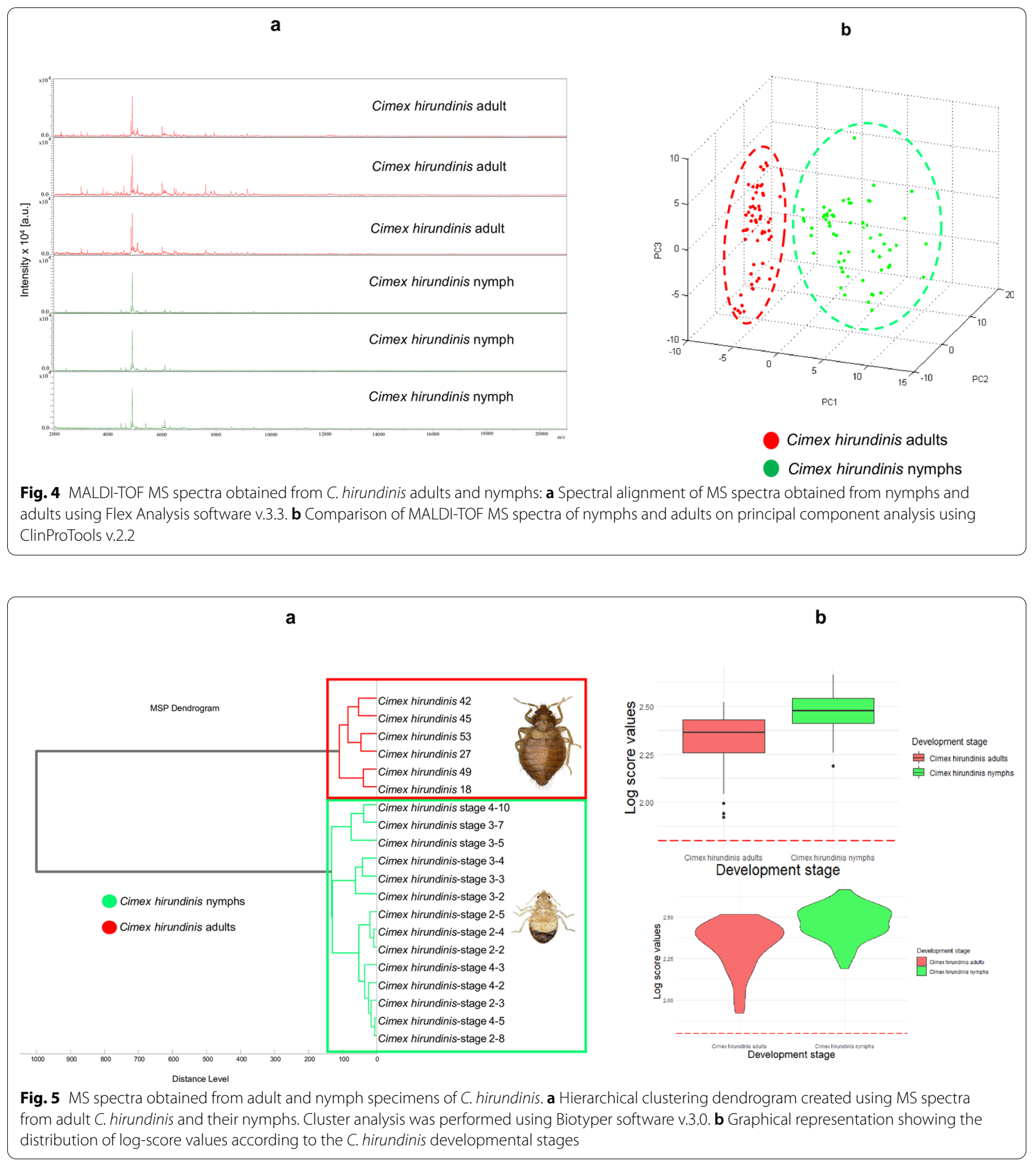


\section{MS identification of $\boldsymbol{C}$. hirundinis adults and nymphs}

To validate the species identification by MALDI-TOF MS, five high-quality spectra of the adult stage and four spectra of the nymphal stage were randomly selected for database creation using MALDI-Biotyper 3.0 (Table 2). A blind test against our MS in-house database was carried out using the remaining spectra. The results showed that $100 \%(57 / 57)$ adult stage specimens were correctly identified with LSVs between 1.922 and 2.518. Cimex hirundinis nymphs were accurately identified, 100\% (46/46), at the species level with LSVs between 2.188 and 2.665 (Table 2). All log-score values obtained for adults and nymphs are represented in Fig. 5b. For nymphs, the LSV mean was $2.461 \pm 0.100$ and the median was 2.476 . For adults, the LSV mean was $2.328 \pm 0.143$ and the median was 2.363 .

\section{Microorganism screening}

One hundred fifteen specimens of $C$. hirundinis, including 65 adults and 50 nymphs, were first screened for the detection of microorganisms by qPCR. Of the $C$. hirundinis specimens, 99\% (113/115) tested positive for Wolbachia spp. (23S) (Table 3). Four sequences of $16 S$ obtained from specimens positive for Wolbachia were identical to each other and showed 100\% homology with the sequence of Wolbachia massiliensis isolated in $C$. hemipterus collected in Senegal (GenBank accession no. CP061738). Similarly, the NCBI BLAST analysis of ftsZ sequences revealed that the sequences were $100 \%$ identical to the sequence of W. massiliensis (GenBank accession no. CP061738) (Table 3). The phylogenetic analyses using the maximum likelihood method showed that the obtained sequences belonged to the new $\mathrm{T}$ supergroup and clustered with $W$. massiliensis isolated from $C$. hemipterus for both genes (Fig. 6a and b). No Bartonella spp., Rickettsia spp., Borrelia spp. and C. burnetii were detected.

\section{Discussion}

MALDI-TOF MS has increasingly been used in the clinical microbiology field for rapid and reliable microorganism classification, and its advantages are currently driving its application in routine microbiological laboratories [26]. More recently, this proteomic tool has also proven its effectiveness in malacology [40]. Several entomological researchers have reported the usefulness of MALDITOF MS as a time-saving, effective and less laborious approach for the identification of various arthropods

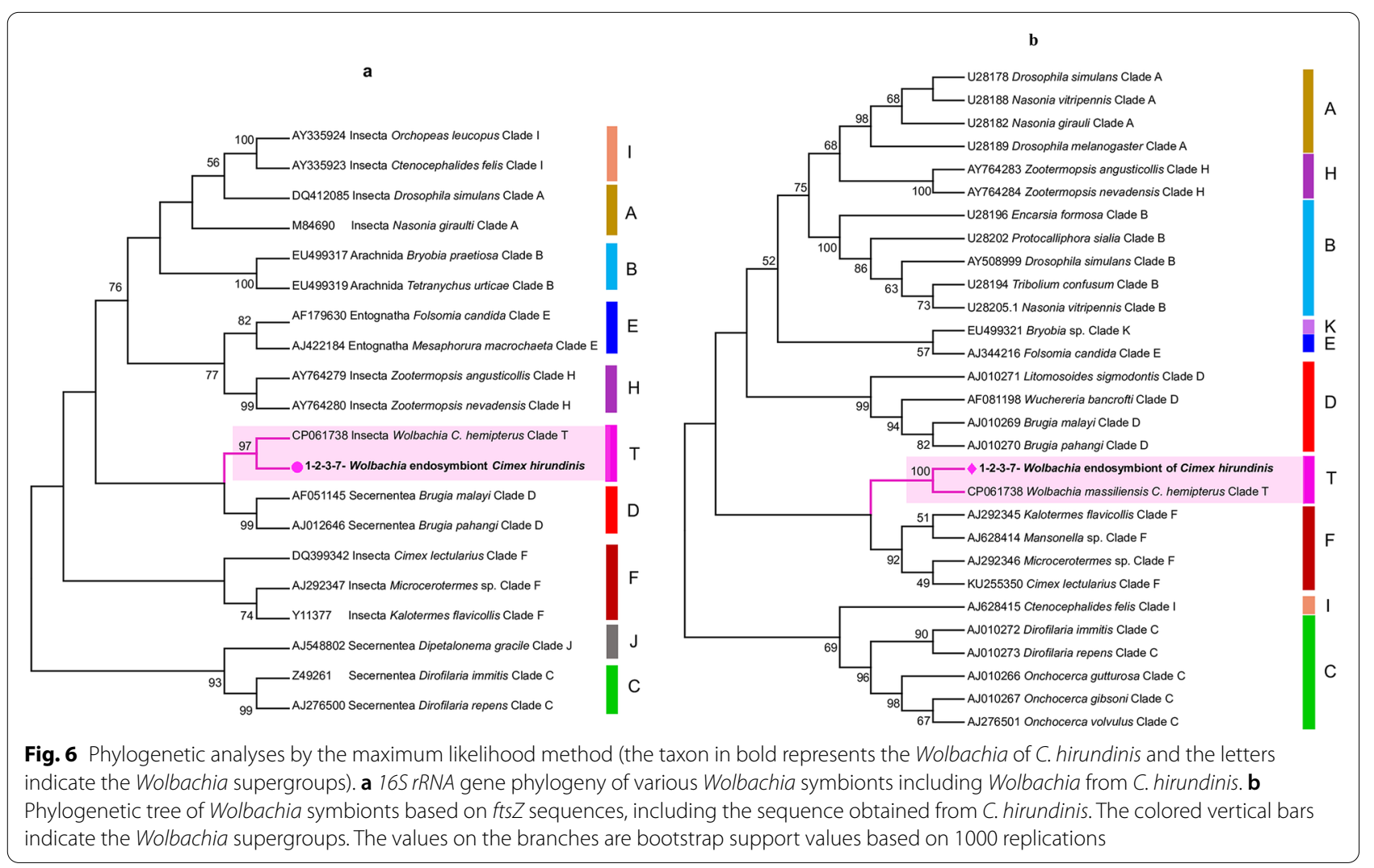


(ticks, fleas, mosquitoes, bed bugs, biting midges, triatomines), targeting different body parts used for protein extraction that generate specific spectra for each species $[25,41-45]$.

The identification of species of the genus Cimex is complicated because it is based on different proportional measurements of the ratio between the length and the width of the pronotum and the length of bristles on the sides of the pronotum [6]. In addition, the use of this criterion alone is not enough to differentiate between species because of the closeness to the cutoff ratio of 2.5 $[6,46]$. Therefore, in the present work, we showed the usefulness of MALDI-TOF MS as a complementary and alternative tool to rapidly identify swallow bug species (C. hirundinis) stored at $-20{ }^{\circ} \mathrm{C}$, without requiring any entomological expertise. MALDI-TOF MS sample preparation is conditioned by different parameters (body part used, preservation method, extraction solution volume adjusted for protein extraction, homogenization method) that can affect the MS spectra quality [24]. Cimex hirundinis is the smallest species in Europe [7, 11]. Furthermore, if we compare this species (C. hirundinis) morphologically with the two bed bug species, it is noticeably smaller (Fig. 2a). Consequently, for the MS identification of nymphs, we selected the cephalothorax (head and thorax) as the body part and the extraction solution volume was adjusted to $15 \mu \mathrm{l}$, as the nymphs were smaller than adults. Moreover, we used glass beads as disruptors because they provided a simple, practical sample preparation and do not require any previous experience compared to glass powder. The current findings agree with previous studies on the ability of MALDI-TOF MS to distinguish between arthropod species [24, 27].

Based on the morphological criteria, the specimens collected from the house martin swallows were all identified as $C$. hirundinis at different stages, including adults and nymphs. In this study, we report the first case of swallow bug (C. hirundinis) invasion of a habitation in France (Fig. 1b-d). Hansel et al. [22] reported a similar case of human infestation by martin bugs (C. hirundinis) in Italy. Moreover, other human infestation cases with swallow bugs have been reported in the US and Japan [21, 47]. To date, in France, in addition to $C$. hirundinis we have found two species ( $C$. hemipterus and $C$. lectularius) that bite and feed on human blood [5, 48, 49]. In the past, Lugger (1896) stated that bugs comparable to human bed bugs attacked swallows and bats. Those bugs were spotted in swallow nests, and they often reached human habitations, but morphologically the body was relatively smaller. Also, it has been previously reported that the American swallow bug (C. vicarius) was identical in general shape to the common bed bug (C. lectularius), but that swallow bug was smaller and had more bristles [50].
In the US, in the 1890s and 1900s, swallow bugs seem to have infested human habitations and been misidentified as bed bugs $[4,51]$. Currently, most people would find it difficult to differentiate between $C$. lectularius and $C$. hemipterus [52]. Even if positively identifying bed bug infestation, they probably would not be able to discriminate the species. Consequently, when a bed bug infestation is considered, it is crucial to examine and identify the species, because in some cases the infestation might be due to either swallow bugs or bat bugs [22, 53]. In such cases, the application of the MALDI TOF MS approach is very interesting and recommended because it allows rapid and specific identification of the bugs, particularly when morphological identification becomes problematic for clinicians at the species level [23]. As recently stated, bed bugs were probably either misidentified as cockroaches because of their small size or not considered as insects at all in their early stages [23]. Here, we highlight the advantage of the MALDI-TOF MS technique to circumvent the drawbacks of morphological identification.

The upgrade of our in-house database with MS reference spectra of the relative method resulted in $46 / 46$ (100\%) C. hirundinis nymphs and 57/57 (100\%) C. hirundinis adult specimens (Table 2) correctly and reliably identified at the species level with LSV $>1.8$. Nymph identification was based only on size, and we estimated three stages, stage 2, 3 and 4 . The dendrogram of MS spectra confirmed that the clustering was not observed according to nymphal stages, and this is explained by the fact that the nymph sizes were so diverse. Consequently, we could not perform a robust interpretation of results, but this does not affect the reliability of this tool. However, further studies are necessary to precisely identify the five nymphal stages of laboratory-reared C. lectularius and C. hemipterus.

In the current study, we demonstrated the strength of the congruence among MALDI-TOF MS, morphological and molecular identification. There was no ambiguity in the identification at the species level, which shows that this proteomic tool is fully valid, in concordance with other previous studies [27]. The molecular data analysis was based on the COI gene. This marker is widely used for different taxonomic and phylogenetic questions within Cimicidae and in the genus Cimex [39, 54]. Balvin et al. [39] proposed the genus Oeciacus as a synonym of Cimex based on molecular data analyses. Like Schuh and Weirauch [55], we followed this proposition in our publication.

In the microorganism screening section of our work, no pathogens were detected. To the best of our knowledge, infectious agents have not yet been documented in C. hirundinis, and it has never been proposed as a vector for human pathogens. However, one report mentioned $C$. 
Table 3 Wolbachia characterization based on 165 and fts $Z$

\begin{tabular}{|c|c|c|c|c|c|c|c|}
\hline Morpho ID & Host & Country/province & $\begin{array}{l}\text { No. of specimens } \\
\text { positive for } \\
\text { Anaplasmataceae } \\
\text { spp. (\%) }\end{array}$ & $\begin{array}{l}\text { No. of specimens } \\
\text { positive for } \\
\text { Wolbachia spp. (\%) }\end{array}$ & $\begin{array}{l}\text { 16SrRNA_\%ID } \\
\text { GenBank_- } \\
\text { Accession } \\
\mathrm{n}=\text { sequence }\end{array}$ & $\begin{array}{l}\text { ftsZ gene_\%ID } \\
\text { GenBank_- } \\
\text { Accession } \\
n=\text { sequence }\end{array}$ & Supergroup \\
\hline C. hirundinis & Delichon urbicum & France/Toulouse & 113/115 (99\%) & 113/115 (99\%) & $\begin{array}{l}100 \% \text { W. massil- } \\
\text { iensis } \\
(\mathrm{CP} 061738.1) \\
(n=4)\end{array}$ & $\begin{array}{l}100 \% \text { W. massil- } \\
\text { iensis } \\
\text { (CP061738.1) } \\
(n=4)\end{array}$ & $\mathrm{T}$ \\
\hline
\end{tabular}

hirundinis as a potential vector of paramyxovirus type 4 $(0.1 \%$ infection rate in adult bugs and $0.4 \%$ in second to fifth nymphal stages, showing transstadial transmission) [56]. On the other hand, some arboviruses have been isolated from $C$. vicarius, emphasizing its vectorial role in transmitting the Buggy Creek virus, which causes western equine encephalitis. This raises a question about possible transmission to humans and livestock $[13,57,58]$.

We detected a novel endosymbiont, Wolbachia, previously reported as $W$. massiliensis in the $C$. hirundinis studied here. Recently, this new strain was first isolated in C. hemipterus collected from Senegal and then described as a new clade (Clade T) [59]. In our study, we report for the first time to our knowledge a novel Wolbachia in the genus Cimex, specifically in the European swallow bug (C. hirundinis), of which the sequences had $100 \%$ homology with both $16 S$ and $f t s Z$ sequences belonging to the T-supergroup strain (W. massiliensis). Based on previous studies, the infection of Wolbachia species of the $F$ clade was common in the Cimicinae subfamily, and infection in the A clade is prevalent in the Afrocimicinae and Haematosiphoninae subfamilies [60]. At present, T-supergroup infections are introduced in two different species, $C$. hirundinis and $C$. hemipterus, which belong to the Cimicidae subfamily and originated from two different continents. Conversely, Wolbachia in the American swallow bug (C. vicarius) is phylogenetically classified in the F-supergroup [61]. In addition, a detailed study on Wolbachia diversity in bed bugs (C. lectularius) collected from different locations in France as well as other studies reported that the Wolbachia strain detected in $C$. lectularius belonged to the F supergroup [60-62]. Also, our findings revealed that the prevalence of Wolbachia obtained in studied $C$. hirundinis was visibly higher than that reported in C. lectularius from France [62]. In our study, we report for the first time to our knowledge the phylogenetic characterization of Wolbachia infecting $C$. hirundinis, revealing its classification in a new, recently discovered supergroup ( $\mathrm{T}$ supergroup) associated with C. hemipterus. Thus, we support the suggestion made by Ros et al. [63] on the possibility of discovering other supergroups that taxonomically enlarge Wolbachia diversity as various potential host species are examined and screening methods improve.

\section{Conclusion}

In the present study, we report for the first time to our knowledge a case of human infestation by swallow bugs (C. hirundinis) in France. This raises awareness of a new infestation that may easily be mistaken for bed bug infestation. Accordingly, in bed bug control missions, it is recommended to identify bird nests in the buildings or the surroundings, and the bugs involved, to avoid infestation recurrences. In addition, we showed the usefulness and robustness of MALDI-TOF MS in the rapid identification of adults and nymphs of $C$. hirundinis specimens with minimal sample requirements. However, further studies are required to validate the reliability of the MALDITOF MS protocol for other Cimicidae species to be fully incorporated in diagnostic routines. In this work, we also seized the opportunity to phylogenetically characterize the novel Wolbachia strain (W. massiliensis) infecting $C$. hirundinis and compared it to other recognized Wolbachia clades obtained from different arthropods. It is necessary to note the importance of identifying $\mathrm{Wol}$ bachia diversity in certain Cimicids infesting humans for control purposes.

\section{Abbreviations}

COl: Cytochrome c oxidase I; RNA: Ribonucleic acid; qPCR: Quantitative polymerase chain reaction.

\section{Supplementary Information}

The online version contains supplementary material available at https://doi. org/10.1186/s13071-021-05073-x.

Additional file 1: Figure S1. Digital microscope (DM) and scanning electron microscope images (SEM) showing a ventral view of $C$. hirundinis: male intromittent organ (a and $\mathbf{c}$ ); female paragenital sinus ( $\mathbf{b}$ and $\mathbf{d}$ ).

Additional file 2: Figure S2. SEM showing a representation of an egg and nymphs at different stages of C. hirundinis. a egg, $\mathbf{b}$ nymph II, $\mathbf{c}$ nymph III, d nymph IV. The nymphal stages were identified based on body size.

Additional file 3: Dataset S1. COI sequences of $C$. hirundinis adults and nymphs.

Additional file 4: Dataset S2. 165 and ftsZ sequences of Wolbachia isolated from C. hirundinis.

\section{Acknowledgements}

We thank Tristan and Marie Effroy, who helped us with specimen collections and also Dr. Oleg Mediannikov. 


\section{Authors' contributions}

FZH, PP and J-MB conceived the study. FZH and J-MB performed the experiments. FZH and AZD carried out the data analysis. FZH and PP wrote the manuscript. All authors read and approved the final manuscript.

\section{Funding}

This study was supported by the Institut Hospitalo-Universitaire (IHU) Méditerranée Infection, the National Research Agency under the "Investissements d'avenir" programme, reference ANR-10-IAHU-03, the Région Provence Alpes Côte d'Azur and European FEDER PRIMI funding.

\section{Availability of data and materials}

COl gene sequences of C. hirundinis: OK077757, OK077758, OK077759, OK077760 and OK077761. All FASTA sequences for the Wolbachia isolated from C. hirundinis are available in Additional file 4: Dataset S2.

\section{Declarations}

\section{Consent for publication}

Not applicable.

\section{Competing interests}

The authors declare that they have no competing interests.

\section{Author details}

${ }^{1} \mathrm{HUU}$-Méditerranée Infection, Marseille, France. ${ }^{2}$ Aix Marseille Univ, IRD, AP-HM, SSA, VITROME, Marseille, France.

Received: 12 September 2021 Accepted: 16 October 2021 Published online: 27 November 2021

\section{References}

1. Krinsky WL. True bugs (Hemiptera). In: Mullen G, Durden L, editors. Med Vet Entomol. Academic Press, San Diego, CA; 2002. p. 67-86.

2. Henry TJ. Biodiversity of Heteroptera. In: Foottit RG, Adler PH, editors. Insectbiodiversity: science and society. Oxford: blackwell publishing; 2009. p. 223-63

3. Reinhardt K, Siva-Jothy MT. Biology of the bed bugs (Cimicidae). Annu Rev Entomol. 2007:52:351-74.

4. Schaefer CW, Panizzi AR. Heteroptera of economic importance. Boca Raton: CRC Press; 2000. p. 3-8.

5. Parola P, Izri A. Bedbugs. N Engl J Med. 2020;382:2230-7.

6. Usinger RL. Monograph of Cimicidae (Hemiptera-Heteroptera). Annapolis: Entomological Society of America; 1966. p. 585

7. Péricart J. Hémiptères: Anthocoridae, Cimicidae et Microphysidae de I'Ouest paléarctique. Bull la société Entomol Fr; 1973. p. 228-9.

8. Eduardo I, Faúndez MAC. Bed bugs are back and also arriving is the southernmost record of Cimex lectularius (Heteroptera: Cimicidae) in South America. J Med Entomol. 2014;51:1073-6.

9. Pereira RM, de Carvalho Campos AE, Justi J, Lage MR. The bed bug resurgence in Latin America. Adv Biol Manag Mod Bed Bugs. 2018. p. 51-57 https://doi.org/10.1002/9781119171539.ch4

10. Cambronero-Heinrichs JC, Sánchez-Portilla LS, Calderón-Arguedas Ó, Troyo A. Cimex lectularius Linnaeus, 1758 (Hemiptera: Cimicidae) in Costa Rica: first case report confirmed by molecular methods in Central America. J Med Entomol. 2020;57:969-73.

11. Kassianoff $L$. Étude morphologique et biologique de la famille des cimicidés. Ann Parasitol Hum Comparée. 1937;15:97-124.

12. Delaunay P, Blanc V, Del Giudice P, Levy-Bencheton A, Chosidow O, Marty P, et al. Bedbugs and infectious diseases. Clin Infect Dis. 2011;52:200-10.

13. Brown CR, Brown MB. Between-group transmission dynamics of the swallow bug, Oeciacus vicarius. J Vector Ecol. 2005;30:137-43.

14. Brown CR, Brown MB. Group size and ectoparasitism affect daily survival probability in a colonial bird. Behav Ecol Sociobiol. 2004;56:498-511.

15. Brown CR, Brown MB. Ectoparastism as a cost of coloniality in cliff swallows (Hirundo pyrrhonota). Ecology. 1986;67:1206-18.

16. Loye JE. Oeciacus vicarius (Hemiptera: Cimicidae). Ent Méd Parasitol. 1985:23:133-9.
17. Országh I, Krumpál M, Cyprich D. Contribution to the knowledge of the martin bug -Oeciacus hirundinis (Hetroptera, Cimicidae) in Czechoslovakia. Zborník Slov Národného Múzea, Prírodné Vedy. 1990;36:43-60.

18. Brown CR, Moore AT, Young GR, Padhi A, Komar N. Isolation of buggy creek virus (Togaviridae: Alphavirus) from field-collected eggs of Oeciacus vicarius (Hemiptera: Cimicidae). J Med Entomol. 2009;46:375-9.

19. Brown CR, Moore AT, Young GR, Komar N. Persistence of buggy creek virus (Togaviridae, Alphavirus) for two years in unfed swallow bugs (Hemiptera: Cimicidae: Oeciacus vicarius). J Med Entomol. 2010;47:436-41.

20. Monath TP, Lazuick JS, Cropp CB, Rush WA, Calisher CH, Kinney RM, et al. Recovery of tonate virus ("bijou bridge" strain), a member of the Venezuelan equine encephalomyelitis virus complex, from cliff swallow nest bugs (Oeciacus vicarius) and nestling birds in North America. Am J Trop Med Hyg. 1980;29:969-83.

21. Beatty NL, Klotz SA, Elliott SP. Hematophagous ectoparasites of cliff swallows invade a hospital and feed on humans. Clin Infect Dis. 2017;65:2119-21.

22. Hansel K, Bianchi L, Principato M, Moretta I, Principato S, Lanza F, et al. Occupational human infestation due to "Martin bug" (Oeciacus hirundinis, Hemiptera: Cimicidae). Int J Dermatol. 2019:58:e115-6.

23. Laroche M, Bérenger JM, Delaunay $P$, Charrel R, Pradines B, Berger F, et al. Medical entomology: a reemerging field of research to better understand vector-borne infectious diseases. Clin Infect Dis. 2017;65:S30-8.

24. Yssouf A, Almeras $L$, Raoult D, Parola P. Emerging tools for identification of arthropod vectors. Future Microbiol. 2016;11:549-66.

25. Benkacimi L, Gazelle G, El Hamzaoui B, Bérenger JM, Parola P, Laroche M. MALDI-TOF MS identification of Cimex lectularius and Cimex hemipterus bedbugs. Infect Genet Evol. 2020;85:104536. https://doi.org/10.1016/j. meegid.2020.104536.

26. Seng P, Rolain JM, Fournier PE, La Scola B, Drancourt M, Raoult D. MALDITOF-mass spectrometry applications in clinical microbiology. Future Microbiol. 2010;5:1733-54.

27. Sevestre J, Diarra AZ, Laroche M, Almeras L, Parola P. Matrix-assisted laser desorption/ionization time-of-flight mass spectrometry: an emerging tool for studying the vectors of human infectious diseases. Future Microbiol. 2021;16:323-40

28. Folmer $\mathrm{O}$, Black $M$, Hoeh W, Lutz R, Vrijenhoek R. DNA primers for amplification of mitochondrial cytochrome c oxidase subunit I from diverse metazoan invertebrates. Mol Mar Biol Biotechnol. 1994;3:294-9.

29. Altschul SF, Gish W, Miller W, Myers EW, Lipman DJ. Basic local alignment search tool. J Mol Biol. 1990;215:403-10.

30. Kumar S, Stecher G, Tamura K. MEGA7: molecular evolutionary genetics analysis version 7.0 for bigger datasets. Mol Biol Evol. 2016;33:1870-4.

31. Kimura M. A simple method for estimating evolutionary rates of base substitutions through comparative studies of nucleotide sequences. J Mol Evol. 1980;16:111-20.

32. Rambaut A. Tree figure drawing tool version 1.4.2.2006-2014. 2014. http:// tree.bio.ed.ac.uk/.

33. Diarra AZ, Almeras L, Laroche $M$, Berenger JM, Koné AK, Bocoum Z, et al. Molecular and MALDI-TOF identification of ticks and tick-associated bacteria in Mali. PLoS Negl Trop Dis. 2017. https://doi.org/10.1371/journal. pntd.0005762.

34. Yssouf A, Almeras L, Terras J, Socolovschi C, Raoult D, Parola P. Detection of Rickettsia spp in ticks by MALDI-TOF MS. PLoS Negl Trop Dis. 2015:9:1-16.

35. Gomes FM, Hixson BL, Tyner MDW, Ramirez JL, Canepa GE, e Silva TLA, et al. Effect of naturally occurring Wolbachia in Anopheles gambiae s.l. mosquitoes from Mali on Plasmodium falciparum malaria transmission. Proc Natl Acad Sci USA. 2017:114:12566-71.

36. Werren $\mathrm{JH}$, Windsor DM. Wolbachia infection frequencies in insects: evidence of a global equilibrium? Proc Biol Sci. 2000;267(1450):1277-85.

37. Laidoudi Y, Davoust B, Varloud M, Niang EHA, Fenollar F, Mediannikov O. Development of a multiplex qPCR-based approach for the diagnosis of Dirofilaria immitis, D. repens and Acanthocheilonema reconditum. Parasit Vectors. 2020;13:319. https://doi.org/10.1186/s13071-020-04185-0.

38. Tamura K. Estimation of the number of nucleotide substitutions when there are strong transition-transversion and $\mathrm{G}+\mathrm{C}$-content biases. Mol Biol Evol. 1992;9:678-87.

39. Balvín O, Roth S, Vilímová J. Molecular evidence places the swallow bug genus Oeciacus Stål within the bat and bed bug genus Cimex Linnaeus (Heteroptera: Cimicidae). Syst Entomol. 2015;40:652-65. 
40. Hamlili FZ, Thiam F, Laroche M, Diarra AZ, Doucouré S, Gaye PM, et al. MALDI-TOF mass spectrometry for the identification of freshwater snails from Senegal, including intermediate hosts of schistosomes. PLoS Negl Trop Dis. 2021;15: e0009725.

41. Yssouf A, Almeras L, Berenger JM, Laroche M, Raoult D, Parola P. Identification of tick species and disseminate pathogen using hemolymph by MALDI-TOF MS. Ticks Tick Borne Dis. 2015;6:579-86.

42. Yssouf A, Socolovschi C, Leulmi H, Kernif T, Bitam I, Audoly G, et al. Identification of flea species using MALDI-TOF/MS. Comp Immunol Microbiol Infect Dis. 2014;37:153-7.

43. Dieme C, Yssouf A, Vega-Rúa A, Berenger JM, Failloux AB, Raoult D, et al. Accurate identification of Culicidae at aquatic developmental stages by MALDI-TOF MS profiling. Parasit Vectors. 2014;7:544.

44. Müller P, Pflüger V, Wittwer M, Ziegler D, Chandre F, Simard F, et al. Identification of cryptic Anopheles mosquito species by molecular protein profiling. PLoS ONE. 2013;8: e57486.

45. Laroche M, Bérenger JM, Gazelle G, Blanchet D, Raoult D, Parola P. MALDITOF MS protein profiling for the rapid identification of chagas disease triatomine vectors and application to the triatomine fauna of French Guiana. Parasitology. 2018;145:665-75.

46. Zhang J, Xia Y, Wang C, Han D, Ren D, Zheng J, et al. Morphological and molecular identification of tropical bed bugs from two cities of the Pearl River Delta in China. J Med Entomol. 2020;58:471-4.

47. Komatsu N, Nakamura N, Yamauchi T. The cases of human infestation by the swallow bug Oeciacus hirundinis (Hemiptera: Cimicidae). Med Entomol Zool. 2016;67:223-5.

48. Bérenger J-M, Pluot-Sigwalt D. Présence en France de la punaise de lit tropicale, Cimex hemipterus (Fabricius, 1803) (Hemiptera, Heteroptera, Cimicidae). Bull Soc Entomol Fr. 2017;122:423-7.

49. Delaunay P, Benzaquen M, Berenger J, Parola P. Bed bug bites. Dermatol Ther. 2020:33(6):e14341. https://doi.org/10.1111/dth.14341.

50. Myers LE. The American swallow bug, Oeciacus vicarius Horvath (Hemiptera, Cimicidae). Parasitology. 1928;20:159-72.

51. Sailer RI. The bedbug, an old bedfellow that's still with us. Pest Control. 1952;20(10):22-4.

52. Campbell BE, Koehler PG, Buss $L J$, Baldwin RW. Recent documentation of the tropical bed bug (Hemiptera: Cimicidae) in Florida since the common bed bug resurgence. Florida Entomol. 2016;99:549-51.
53. Whyte AS, Garnett PA, Whittington AE. Bats in the belfry, bugs in the bed? Lancet. 2001;357:604.

54. Hornok S, Szőke K, Boldogh SA, Sándor AD, Kontschán J, Tu VT, et al. Phylogenetic analyses of bat-associated bugs (Hemiptera: Cimicidae: Cimicinae and Cacodminae) indicate two new species close to Cimex lectularius. Parasit Vectors. 2017. https://doi.org/10.1186/s13071-017-2376-1.

55. Schuh RT, Weirauch C. True bugs of the world (Hemiptera: Heteroptera): Classification and Natural History. Siri Scientific Press; 2020. p. 768.

56. Gresíková M, Nosek J, Ciampor F, Sekeyová M, Turek R. Isolation of paramyxovirus type 4 from Oeciacus hirundinis bugs. Acta Virol. 1980;24(3):222-3.

57. Hayes RO, Francy DB, Lazuick JS, Smith GC, Gibbs EPJ. Role of the cliff swallow bug (Oeciacus vicarius) in the natural cycle of a western equine Encephalitis-related alphavirus. J Med Entomol. 1977;14:257-62.

58. Rush WA, Francy DB, Smith GC, Cropp CB. Transmission of an arbovirus by a member of the family Cimicidae. Ann Entomol Soc Am. 1980;73:315-8.

59. Laidoudi Y, Levasseur A, Medkour H, Maaloum M, Khedher MB, Sambou $\mathrm{M}$, et al. An earliest endosymbiont, Wolbachia massiliensis sp. Nov., strain pl13 from the bed bug (Cimex hemipterus), type strain of a new supergroup T. Int J Mol Sci. 2020;21:1-18.

60. Sakamoto JM, Rasgon JL. Endosymbiotic bacteria of bed bugs: evolution, ecology and genetics. Am Entomol. 2006;52:119-22.

61. Rasgon JL, Scott TW. Phylogenetic characterization of Wolbachia symbionts infecting Cimex lectularius L. and Oeciacus vicarius Horvath (Hemiptera: Cimicidae). J Med Entomol. 2004;41:1175-8.

62. Akhoundi M, Cannet A, Loubatier C, Berenger JM, Izri A, Marty P, et al. Molecular characterization of Wolbachia infection in bed bugs (Cimex lectularius) collected from several localities in France. Parasite. 2016. https://doi.org/10.1051/parasite/2016031.

63. Ros VID, Fleming VM, Feil EJ, Breeuwer JAJ. How diverse is the genus Wolbachia? multiple-gene sequencing reveals a putatively new Wolbachia supergroup recovered from spider mites (Acari: Tetranychidae). Appl Environ Microbiol. 2009;75:1036-43.

\section{Publisher's Note}

Springer Nature remains neutral with regard to jurisdictional claims in published maps and institutional affiliations.
Ready to submit your research? Choose BMC and benefit from:

- fast, convenient online submission

- thorough peer review by experienced researchers in your field

- rapid publication on acceptance

- support for research data, including large and complex data types

- gold Open Access which fosters wider collaboration and increased citations

- maximum visibility for your research: over $100 \mathrm{M}$ website views per year

At BMC, research is always in progress.

Learn more biomedcentral.com/submissions 